\title{
Large impact basins on Mercury: Global distribution, characteristics, and modification history from MESSENGER orbital data
}

\author{
Caleb I. Fassett, ${ }^{1}$ James W. Head, ${ }^{2}$ David M. H. Baker, ${ }^{2}$ Maria T. Zuber, ${ }^{3}$ David E. Smith,,${ }^{3,4}$ \\ Gregory A. Neumann, ${ }^{4}$ Sean C. Solomon, ${ }^{5,6}$ Christian Klimczak, ${ }^{5}$ Robert G. Strom, ${ }^{7}$ \\ Clark R. Chapman, ${ }^{8}$ Louise M. Prockter, ${ }^{9}$ Roger J. Phillips, ${ }^{8}$ Jürgen Oberst, ${ }^{10}$ \\ and Frank Preusker ${ }^{10}$
}

Received 6 June 2012; revised 31 August 2012; accepted 5 September 2012; published 27 October 2012.

[1] The formation of large impact basins (diameter $D \geq 300 \mathrm{~km}$ ) was an important process in the early geological evolution of Mercury and influenced the planet's topography, stratigraphy, and crustal structure. We catalog and characterize this basin population on Mercury from global observations by the MESSENGER spacecraft, and we use the new data to evaluate basins suggested on the basis of the Mariner 10 flybys. Forty-six certain or probable impact basins are recognized; a few additional basins that may have been degraded to the point of ambiguity are plausible on the basis of new data but are classified as uncertain. The spatial density of large basins $(D \geq 500 \mathrm{~km})$ on Mercury is lower than that on the Moon. Morphological characteristics of basins on Mercury suggest that on average they are more degraded than lunar basins. These observations are consistent with more efficient modification, degradation, and obliteration of the largest basins on Mercury than on the Moon. This distinction may be a result of differences in the basin formation process (producing fewer rings), relaxation of topography after basin formation (subduing relief), or rates of volcanism (burying basin rings and interiors) during the period of heavy bombardment on Mercury from those on the Moon.

Citation: Fassett, C. I., et al. (2012), Large impact basins on Mercury: Global distribution, characteristics, and modification history from MESSENGER orbital data, J. Geophys. Res., 117, E00L08, doi:10.1029/2012JE004154.

\section{Introduction}

[2] The importance of impact craters and basins in the geologic evolution of Mercury was apparent on the basis of

\footnotetext{
${ }^{1}$ Department of Astronomy, Mount Holyoke College, South Hadley, Massachusetts, USA.

${ }^{2}$ Department of Geological Sciences, Brown University, Providence, Rhode Island, USA.

${ }^{3}$ Department of Earth, Atmospheric, and Planetary Sciences, Massachusetts Institute of Technology, Cambridge, Massachusetts, USA.

${ }^{4}$ NASA Goddard Space Flight Center, Greenbelt, Maryland, USA.

${ }^{5}$ Department of Terrestrial Magnetism, Carnegie Institution of Washington, Washington, DC, USA.

${ }^{6}$ Lamont-Doherty Earth Observatory, Columbia University, Palisades, New York, USA.

${ }^{7}$ Lunar and Planetary Laboratory, University of Arizona, Tucson, Arizona, USA.

${ }^{8}$ Department of Space Sciences, Southwest Research Institute, Boulder, Colorado, USA.

${ }^{9}$ The Johns Hopkins University Applied Physics Laboratory, Laurel, Maryland, USA.

${ }^{10}$ Institute of Planetary Research, German Aerospace Center, Berlin, Germany.

Corresponding author: C. I. Fassett, Department of Astronomy, Mount Holyoke College, South Hadley, MA 01075, USA. (cfassett@mtholyoke.edu)

(C)2012. American Geophysical Union. All Rights Reserved. 0148-0227/12/2012JE004154
}

the first Mariner 10 images and earliest geological mapping of the planet [e.g., Murray et al., 1974; Trask and Guest, 1975]. The initial geological studies of Mercury were based on the premise that its cratering record is similar to that of the Moon, although later examination of Mariner 10 data suggested a variety of important differences: (1) There is a deficiency in the density of craters less than $\sim 40-50 \mathrm{~km}$ in diameter on Mercury compared with the Moon, even in heavily cratered terrain [Strom, 1977; Strom and Neukum, 1988]. (2) Secondary craters are more numerous and prominent on Mercury than on the Moon [Gault et al., 1975; Scott, 1977; Spudis and Guest, 1988]. (3) There is a higher average crater density observed on the smooth plains of Mercury than on the lunar maria, as well as less variation in the crater density on plains surfaces on Mercury. This last observation has been interpreted to indicate that widespread volcanism terminated earlier on Mercury than on the Moon and may have occurred in a more punctuated manner [Basaltic Volcanism Study Project, 1981; Spudis and Guest, 1988; Strom and Neukum, 1988]. (4) There is a possible deficiency in the density of large basins on Mercury relative to the Moon [Malin, 1976; Wood and Head, 1976; Schaber et al., 1977; Frey and Lowry, 1979], although this inference was disputed by Spudis and Strobell [1984] and Spudis and Guest [1988], and the discussion was complicated by the 
Table 1. Certain and Probable Impact Basins on Mercury, $D \geq 300 \mathrm{~km}^{\mathrm{a}}$

\begin{tabular}{|c|c|c|c|c|c|c|c|c|c|}
\hline Basin Name/ID & $D(\mathrm{~km})$ & $\begin{array}{l}\text { Latitude } \\
\left({ }^{\circ} \mathrm{N}\right)\end{array}$ & $\begin{array}{l}\text { Longitude } \\
\quad\left({ }^{\circ} \mathrm{E}\right)\end{array}$ & Confidence & $\begin{array}{c}\text { Rim } \\
\text { Completeness } \\
(\%)\end{array}$ & $\begin{array}{l}\text { Visible } \\
\text { Ejecta }\end{array}$ & $\begin{array}{l}\text { Additional } \\
\text { Ring? }\end{array}$ & Source & Note \\
\hline Caloris & 1550 & 31.4 & 160.3 & Certain & 95 & Yes & Possible & M10 & $\begin{array}{l}\text { Murray et al. [1974]; } \\
\text { SG1 }\end{array}$ \\
\hline b30 & 1390 & 15.9 & 21.1 & Probable & 20 & & & Flyby DEM & Preusker et al. [2011] \\
\hline Matisse-Repin & 950 & -24.3 & -75.6 & Certain & 50 & & & M10 & SG11 \\
\hline Andal-Coleridge & 830 & -42.6 & -51.0 & Probable & 50 & & & M10 / DEM & SG10 \\
\hline Borealis & 790 & 71.0 & -81.0 & Probable & 20 & & & Orbit & $\begin{array}{l}\text { SG14 (smaller; } \\
\text { relocated) }\end{array}$ \\
\hline Sobkou & 770 & 33.4 & -133.0 & Certain & 80 & Yes & Possible & M10 & SG5 \\
\hline b31 & 770 & 36.6 & 3.6 & Probable & 20 & & & Flyby DEM & Preusker et al. [2011] \\
\hline b45 & 770 & 45.3 & 43.3 & Probable & 20 & & & Orbit & \\
\hline b36 & 730 & -7.6 & 21.6 & Certain & 60 & Yes & & Orbit & \\
\hline b34 & 720 & -30.1 & 6.0 & Probable & 30 & & & Orbit DEM & \\
\hline Rembrandt & 720 & -33.0 & 87.8 & Certain & 95 & Yes & Yes & Flybys & Watters et al. [2009a] \\
\hline Vincente-Yakovlev & 690 & -52.6 & -162.1 & Probable & 50 & & & M10 / DEM & SG12 \\
\hline Budh & 680 & 17.2 & -151.7 & Probable & 30 & & & M10 & SG16 \\
\hline Beethoven & 630 & -20.8 & -123.9 & Certain & 95 & Yes & Possible & M10 & Schaber et al. [1977] \\
\hline b54 & 610 & -1.8 & -59.4 & Probable & 20 & & & Orbit DEM & \\
\hline b12 & 550 & 3.7 & 74.5 & Probable & 10 & & & Flybys & \\
\hline Derzhavin-Sor Juana & 580 & 52.3 & -28.3 & Probable & 40 & & & M10 & SG15 \\
\hline Tolstoj & 490 & -16.4 & -165.1 & Certain & 60 & Yes & Yes & M10 & $\begin{array}{l}\text { Murray et al. [1974]; } \\
\text { SG2 }\end{array}$ \\
\hline Hawthorne-Riemenschneider & 470 & -55.9 & -105.9 & Probable & 20 & & & M10/DEM & SG18 \\
\hline b33 & 470 & -72.9 & 149.9 & Probable & 50 & & & Orbit & \\
\hline b38 & 470 & -13.4 & -6.6 & Certain & 90 & Yes & Possible & Orbit & \\
\hline b44 & 450 & -10.3 & 102.6 & Probable & 60 & & & Orbit & \\
\hline b37 & 430 & -27.3 & -3.2 & Certain & 80 & Yes & & Orbit & \\
\hline b2 & 420 & -39.0 & -101.4 & Certain & 60 & & & Flybys & \\
\hline Dostoevskij & 410 & -44.5 & -176.5 & Certain & 80 & Yes & Possible & M10 & Murray et al. [1974] \\
\hline b11 & 390 & -2.6 & -56.1 & Probable & 40 & & & Flybys & \\
\hline b27 & 390 & 27.9 & -158.6 & Certain & 60 & & & M10/Orbit & Murray et al. [1974] \\
\hline b39 & 390 & -26.5 & -142.0 & Certain & 60 & & & Orbit & \\
\hline b65 & 390 & -45.8 & -93.9 & Probable & 40 & & & Orbit & \\
\hline b32 & 370 & 55.8 & -10.6 & Probable & 20 & & & Flyby DEM & Preusker et al. [2011] \\
\hline Shakespeare & 360 & 48.9 & -152.3 & Certain & 50 & & & M10 & $\begin{array}{l}\text { Murray et al. [1974]; } \\
\text { SG4 }\end{array}$ \\
\hline b20 & 360 & -3.1 & -44.2 & Certain & 80 & Yes & & M10 & Murray et al. [1974] \\
\hline b52 & 360 & -30.3 & 153.5 & Probable & 20 & & & Orbit & \\
\hline b41 & 350 & -44.8 & -142.7 & Probable & 20 & & & Orbit & \\
\hline Hiroshige-Mahler & 340 & -23.0 & -17.0 & Probable & 10 & & & M10 & SG7 \\
\hline Chong-Gauguin (smaller) & 330 & 57.1 & -107.9 & Certain & 50 & & Yes & M10/Flybys & SG20 (smaller) \\
\hline Goethe & 320 & 81.4 & -54.3 & Certain & 90 & & & M10 & Schaber et al. [1977] \\
\hline Raphael & 320 & -20.3 & -76.1 & Certain & 80 & Yes & & M10 & Schaber et al. [1977] \\
\hline b6 & 320 & -17.5 & -96.6 & Probable & 60 & & & Flybys & \\
\hline Homer & 310 & -1.7 & -36.8 & Certain & 80 & Yes & Yes & M10 & Murray et al. [1974] \\
\hline b4 & 310 & 28.9 & -113.8 & Probable & 50 & & & M10 & Schaber et al. [1977] \\
\hline b9 & 310 & -25.0 & -98.8 & Probable & 10 & & & Flybys & \\
\hline b40 & 310 & 6.5 & 134.8 & Probable & 40 & & & Orbit & \\
\hline b64 & 310 & -16.2 & 160.8 & Probable & 50 & & & Orbit & \\
\hline Vy-asa & 310 & 49.7 & -84.5 & Certain & 50 & & Possible & M10 & Schaber et al. [1977] \\
\hline b3 & 300 & -50.8 & 92.5 & Probable & 40 & & & Orbit & \\
\hline
\end{tabular}

${ }^{\text {a }}$ The latitude and longitude correspond to the center of each feature. SG is the row number in Table 2 of Spudis and Guest [1988]. Estimated rim completeness is based on best available image data.

fact that different workers used different diameter cutoffs when considering this possible deficiency.

[3] The new observations provided by the MErcury Surface, Space ENvironment, GEochemistry, and Ranging (MESSENGER) spacecraft [Solomon et al., 2001] have prompted fresh examinations of the cratering record of Mercury and have provided a chance to test earlier hypotheses with more global data [e.g., Strom et al., 2008, 2011; Fassett et al., 2011]. New results strongly support the idea that, even in heavily cratered terrains on Mercury, fewer craters are observed than on the lunar highlands for craters with diameter $D$ from 20 to $\sim 128 \mathrm{~km}$ [Fassett et al., 2011; Strom et al., 2011]. The greater influence of secondary craters on Mercury's cratering record is also supported by new data as well [Strom et al., 2008, 2011; Chapman et al., 2011]. In addition, MESSENGER observations appear to be consistent with the interpretation that there is a limited range in the crater density on the areally extensive smooth plains, particularly since the two largest regions of smooth plains (within and around Caloris, and at high northern latitudes) have similar size-frequency distributions for superposed craters [Head et al., 2011; Ostrach et al., 2011].

[4] Although peak-ring basins have been analyzed globally on Mercury [Baker et al., 2011, 2012], the population of the largest basins on Mercury and its similarity to and 
Table 2. Suggested but Unverified Impact Basins on Mercury, $D \geq 300 \mathrm{~km}^{\mathrm{a}}$

\begin{tabular}{|c|c|c|c|c|c|}
\hline Basin Name/ID & Diameter $(\mathrm{km})$ & Latitude $\left({ }^{\circ} \mathrm{N}\right)$ & Longitude $\left({ }^{\circ} \mathrm{E}\right)$ & Source & Note \\
\hline "Basin S”/“Skinakas” b & $\sim 1000-2000$ & 8 & 80 & Telescopic & Ksanfomality [2004] \\
\hline "Medallion" b & $\sim 1000$ & 0 & 60 & Telescopic & Ksanfomality [2008] \\
\hline b68 & 1400 & & & & \\
\hline b57 & 1250 & -16 & 86 & Orbit & \\
\hline Tir & 1250 & 6 & -168 & M10 & SG9 \\
\hline Eitoku-Milton & 1180 & -23 & -171 & M10 & SG13 \\
\hline Bartok-Ives ${ }^{\mathrm{b}}$ & 1175 & -33 & -115 & M10 & SG22 \\
\hline Donne-Moliere & 1060 & 4 & -10 & M10 & SG21 \\
\hline b56 & $\sim 1000-1500$ & -18 & 48 & Orbit & \\
\hline $\mathrm{b} 13^{\mathrm{b}}$ & $\sim 1000$ & 17 & 122 & Radar & Butler et al. [1993] \\
\hline b14 & $\sim 1000$ & 55 & 12 & Radar & Butler et al. [1993] \\
\hline $\mathrm{b} 15^{\mathrm{b}}$ & $\sim 1000$ & -29 & 11 & Radar & Butler et al. [1993] \\
\hline Sadi-Scopus & 930 & -82.5 & -44 & M10 & SG23 \\
\hline Mena-Theophanes & 770 & -1 & -129 & M10 & SG8 \\
\hline b59 & 740 & 49.5 & -120 & Orbit & \\
\hline b16 & 720 & -45.5 & 137.2 & Flybys & \\
\hline b53 & 670 & -0.6 & 140.6 & Orbit & \\
\hline Ibsen-Petrarch ${ }^{\mathrm{b}}$ & 640 & -31 & -30 & M10 & SG17 \\
\hline Brahms-Zola ${ }^{\mathrm{b}}$ & 620 & 59 & -172 & M10 & SG6 \\
\hline b50 & 620 & 56.3 & 68.6 & Orbit & \\
\hline b60 & 620 & 83 & 83 & Orbit & \\
\hline b55 & 580 & 53 & -59.8 & Orbit & \\
\hline b43 & 540 & -1.1 & 149.5 & Orbit & \\
\hline b58 & 530 & -62 & -140 & Orbit & \\
\hline Gluck-Holbein ${ }^{\mathrm{b}}$ & 500 & 35 & -19 & M10 & SG19 \\
\hline $\mathrm{b} 1^{\mathrm{b}}$ & 450 & -8 & -65 & M10 & Malin [1976] \\
\hline b66 & 450 & -53.7 & 148.8 & Orbit & \\
\hline b25 & 440 & -15 & 93 & Flybys & \\
\hline b22 & 400 & 0 & 93 & Flybys & \\
\hline b42 & 400 & -12.8 & 171.2 & Orbit & \\
\hline b51 & 400 & -74.2 & -13.8 & Orbit & \\
\hline b5 & 380 & 27.3 & -146.1 & M10 & Schaber et al. [1977] \\
\hline b47 & 360 & 23.0 & -170.5 & Orbit & \\
\hline b49 & 360 & 55.6 & -28.9 & Orbit & \\
\hline b61 & 360 & 77 & -142.5 & Orbit & \\
\hline $\mathrm{b} 62$ & 360 & 78.5 & 166 & Orbit & \\
\hline b18 & 340 & 10.8 & 65.6 & Flybys & \\
\hline $\mathrm{b} 67$ & 340 & -53.7 & 148.8 & Orbit & \\
\hline b63 & 330 & 31.7 & 99.5 & Orbit & \\
\hline b46 & 320 & -40.6 & 130.2 & Orbit & \\
\hline b48 & 320 & -37.7 & -78.7 & Orbit & \\
\hline
\end{tabular}

${ }^{a}$ Basin names given in quotes have not been approved by IAU but were suggested by earlier workers. SG is the row number in Table 2 of Spudis and Guest [1988].

${ }^{\mathrm{b}}$ Earlier proposals that now appear unlikely to be a correct identification on the basis of current data.

differences from the corresponding lunar basin population has yet to be thoroughly examined with MESSENGER data and is the major focus of this study. In this paper, we (1) reexamine the basins suggested on the basis of earlier data sets, especially Mariner 10 data, (2) document additional basins from the global orbital observations of Mercury by MESSENGER, (3) assess the size-frequency distribution of basins on Mercury from these global observations and compare it with that of the Moon, (4) analyze the characteristics and modification history of basins on Mercury, and (5) briefly explore the interactions on Mercury among volcanism, tectonics, and basin evolution.

\section{Data and Methodology}

[5] The primary data for this study are images and derived topography from MESSENGER's Mercury Dual Imaging System (MDIS) [Hawkins et al., 2007] and altimetric data of the northern hemisphere from the Mercury Laser Altimeter (MLA) [Cavanaugh et al., 2007]. Images from the first solar day of MESSENGER's orbital operations provide nearly global coverage with imaging conditions optimized for morphology. These images have been mosaicked into a $250 \mathrm{~m} / \mathrm{pixel}$ global data set that we used as the base map for our study. Additional mosaics and individual images from Mariner 10 and MESSENGER were examined where they provided additional coverage or were necessary to assess earlier interpretations. All data were imported and analyzed in the ESRI ArcMap geographic information system (GIS) environment with a Mercury datum of $2440 \mathrm{~km}$ radius. The CraterTools extension to ArcMap [Kneissl et al., 2011] was used to derive best-fit circles to the basin rims and to measure basin diameters. We report basin diameters rounded to the nearest $10 \mathrm{~km}$ increment on the basis of the estimated uncertainty of this measurement, although some diameter estimates may be more uncertain, particularly for the most degraded basins.

[6] Basins were mapped systematically by repeated surveying of the MESSENGER image base map at a 1:5 million scale, zooming in as necessary to test the existence of candidate features. Several of the co-authors independently examined the entire data set. We also specifically reexamined basins suggested in earlier studies, most of which 


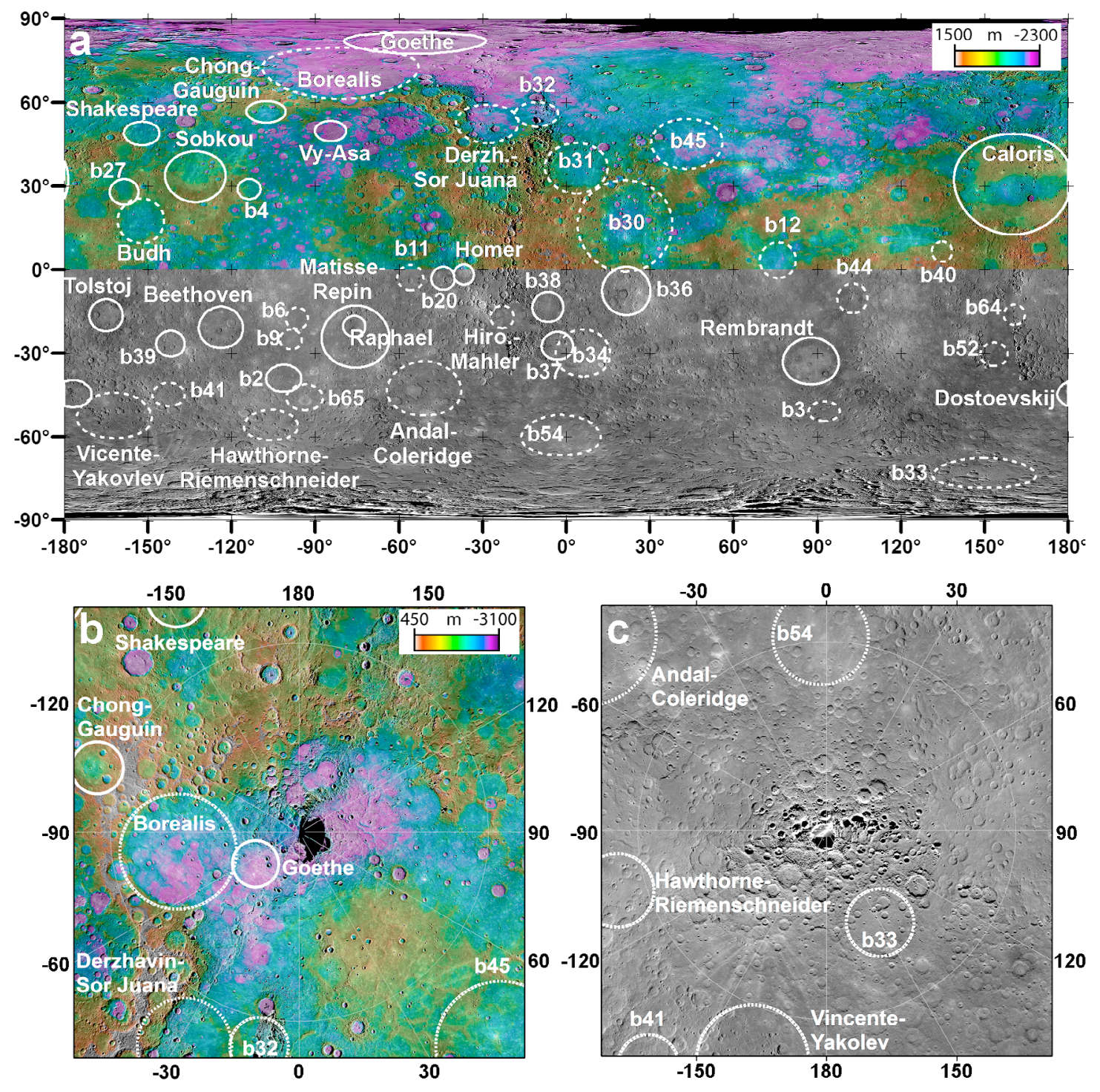

Figure 1. Certain (solid white) and probable (dashed white) impact basins on Mercury determined from MESSENGER data, superposed on a global mosaic of MDIS images in the southern hemisphere and MLA topography in the northern hemisphere. (a) Global view in equidistant cylindrical projection. (b) North polar region. (c) South polar region. Polar views are polar stereographic projections with lines of longitude and latitude shown in $30^{\circ}$ increments. The topographic datum is a sphere of radius $2440 \mathrm{~km}$.

were based on Mariner 10 data [Murray et al., 1974; Malin, 1976; Wood and Head, 1976; Schaber et al., 1977; Frey and Lowry, 1979; Spudis and Guest, 1988]. A few additional basins were suggested on the basis of radar [Butler et al., 1993] and telescopic studies [Ksanfomality, 2004, 2008, 2009, 2011; Ksanfomality and Sprague, 2007].

[7] For both the previously suggested and newly mapped basins, a qualitative confidence for the basin was assigned on the basis of the completeness of the basin rim and rim crest, as well as the presence or absence of additional evidence for a basin, such as ejecta, structure, or topography. Basins were classified as either certain or probable (Table 1), or suggested but unverified (Table 2). All certain features have a distinctive rim or wrinkle ring around at least $50 \%$ of the basin circumference; probable basins may be less than $50 \%$ encircled by a rim, or have other degradation that makes their status less certain. However, these assignments are conservative in that we believe that all certain basins have been correctly classified as impact features and their size estimates and locations are well determined. Most probable basins are also likely to be impact features, but for some, their center location or size is uncertain.

[8] Basins classified as suggested but unverified are ambiguous or unconfirmed in MESSENGER data. Many were suggested on the basis of Mariner 10 or Earth-based telescopic data, but more complete, higher-resolution image coverage and altimetry data from MESSENGER now show that they are not likely to be major impact features. Additional basin candidates are identified here, but because confirming data are lacking they are included in Table 2 . Some basins in Table 2 may nonetheless be impact structures at a highly degraded state of preservation. 


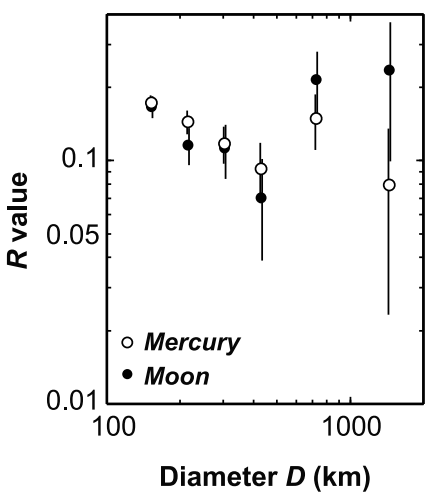

Figure 2. $R$-plot of the spatial density of large craters and basins for all of Mercury, updated with orbital data from Fassett et al. [2011], compared with the Moon. The R-plot normalizes the differential size-frequency distribution by a power law of slope -3 , so within a count region of area $A$, for $n$ craters in the size bin from diameter $a$ to diameter $b$, $R=d^{3} n /[A(b-a)]$, where $d$ is the geometric mean of $a$ and $b$ [see Crater Analysis Techniques Working Group, 1978]. $R$ is a measure of areal density, so the larger the value of $R$, the greater the age of the surface, at least if craters are not in saturation equilibrium. This plot is binned by diameter increments of a factor of $\sqrt{2}$ from $D=128 \mathrm{~km}$ to $D=512 \mathrm{~km}$, above which the diameter increment is a factor of 2 for the largest two bins $(D=512-1024 \mathrm{~km}$ and $D=1024-2048 \mathrm{~km})$. Errors shown for each point are from counting statistics alone $(R / \sqrt{ } n)$. Basin diameters are determined on the basis of their inferred topographic rim, equivalent to the Cordillera ring around the lunar Orientale basin. For fresh basins on both the Moon and Mercury, this rim is commonly expressed as an inward facing topographic scarp. The Moon and Mercury are similar in crater density for $D=128-512 \mathrm{~km}$, but above $D=512 \mathrm{~km}$ there are fewer basins per area on Mercury than on the Moon.

[9] Where possible, features that have been assigned a name by past workers are designated by that name here. Many of the best-preserved basins have been assigned IAUapproved crater names (Beethoven, Dostoevskij, Goethe, Homer, Raphael, Rembrandt, Shakespeare, Tolstoj, Vy-Asa). Others are named here on the basis of the IAU names for associated planitia (Borealis, Budh, Caloris, Sobkou, Tir). Hyphenated names are taken from nearby smaller craters, following the convention for degraded basins on the Moon. For convenience, basins not assigned names by IAU or in the prior literature are listed in Tables 1 and 2 with alphanumerical identifiers (e.g., b1, b2, b3) in arbitrary order.

[10] Peak-ring and medium-sized basins on Mercury have been recently examined by Baker et al. [2011] and Prockter et al. [2012]. Only the two largest peak-ring basins described by Baker et al. [2011] overlap with the size range of the basins considered here.

\section{Results}

\subsection{Density and Size-Frequency Distribution of Certain and Probable Basins on Mercury}

[11] We identified 46 certain or probable basins on Mercury; their sizes and locations are provided in Table 1 and Figure 1. This number $n$ of basins with $D \geq 300 \mathrm{~km}$ is only $\sim 48 \%$ more than documented on the Moon $(n=31)$ with similar recognition criteria [Fassett et al., 2012], despite Mercury having twice the surface area. The spatial density of basins with $D \geq 300 \mathrm{~km}$ normalized to an area of $10^{6} \mathrm{~km}^{2}, N_{\text {Mercury }}(300$ ), is $0.61 \pm 0.09$ (where the cited error is $\pm \sqrt{n} / A$ and $A$ is the measurement area). This density is less than on the Moon, where $N_{\text {Moon }}(300)=0.82 \pm 0.15$, although the uncertainties in the two densities overlap.

[12] However, closer examination reveals that the difference in basin densities is dominated by a difference in the density of basins with $D \geq 500 \mathrm{~km}$, because $N_{\text {Mercury }}(500)=$ $0.23 \pm 0.05$ and $N_{\text {Moon }}(500)=0.37 \pm 0.1$. Figure 2 , an $R$-plot of the full size-frequency distribution of Mercury and the Moon for craters with diameters $128 \mathrm{~km}$ and larger, updated with orbital data, illustrates this density difference for the largest basins. At smaller sizes, in contrast, for large craters and small basins $(D=128-512 \mathrm{~km})$, the densities for the two bodies are nearly the same: $N_{\text {Mercury }}(128)-N_{\text {Mercury }}(512)=$ $4.3 \pm 0.2$ and $N_{\text {Moon }}(128)-N_{\text {Moon }}(512)=3.9 \pm 0.3$ [see also Fassett et al., 2011].

\subsection{Basins Discovered With MESSENGER Orbital Data}

[13] Although a detailed description of the geology of the newly recognized $720 \mathrm{~km}$ diameter Rembrandt impact has been presented earlier [Watters et al., 2009a], many of the other basins that have been seen for the first time in MESSENGER data have yet to be described. Here, we present brief observations of some of these basins.

\subsubsection{The 730-km-Diameter Basin (b36) at $7.6^{\circ} \mathrm{S}$, $21.6^{\circ} \mathrm{E}$}

[14] A basin that is $730 \mathrm{~km}$ in diameter, classified as certain, is centered at $7.6^{\circ} \mathrm{S}, 21.6^{\circ} \mathrm{E}$ (Figure 3). In a few places near the rim, there are possible examples of radial troughs formed by basin ejecta. More prominent sculptured troughs or secondary chains from this basin are found $400 \mathrm{~km}$ to its south $\left(26^{\circ} \mathrm{S}, 22^{\circ} \mathrm{E}\right)$.

[15] The eastern rim and much of the basin interior are superposed by four peak-ring basins [Baker et al., 2011], the youngest of which is Derain [e.g., Prockter et al., 2012] (white arrow, Figure 3). Derain has several anomalous characteristics: between its interior peak ring and exterior rim, it has an exposure of low-reflectance material (LRM) dissimilar from its surroundings [Robinson et al., 2008; Denevi et al., 2009], and its peak ring has been partially removed [Prockter et al., 2012], forming what appear to be hollows [Blewett et al., 2011]. Both hollow formation and LRM exposure within Derain may have been favored in this location because of the pre-existing excavation of material from depth that occurred during formation of the larger, underlying basin. The association of LRM with basins such as Tolstoj and more generally with excavation of materials from depth has been noted earlier [Robinson et al., 2008; Denevi et al., 2009].

[16] No interior rings of this basin are apparent, although even if interior rings were once present, they may have been destroyed and/or buried by the formation of the numerous superposed craters and smaller basins. Lobate scarps are localized near the rim in the southwestern part of the basin, where basin-interior materials have been thrust toward the rim 


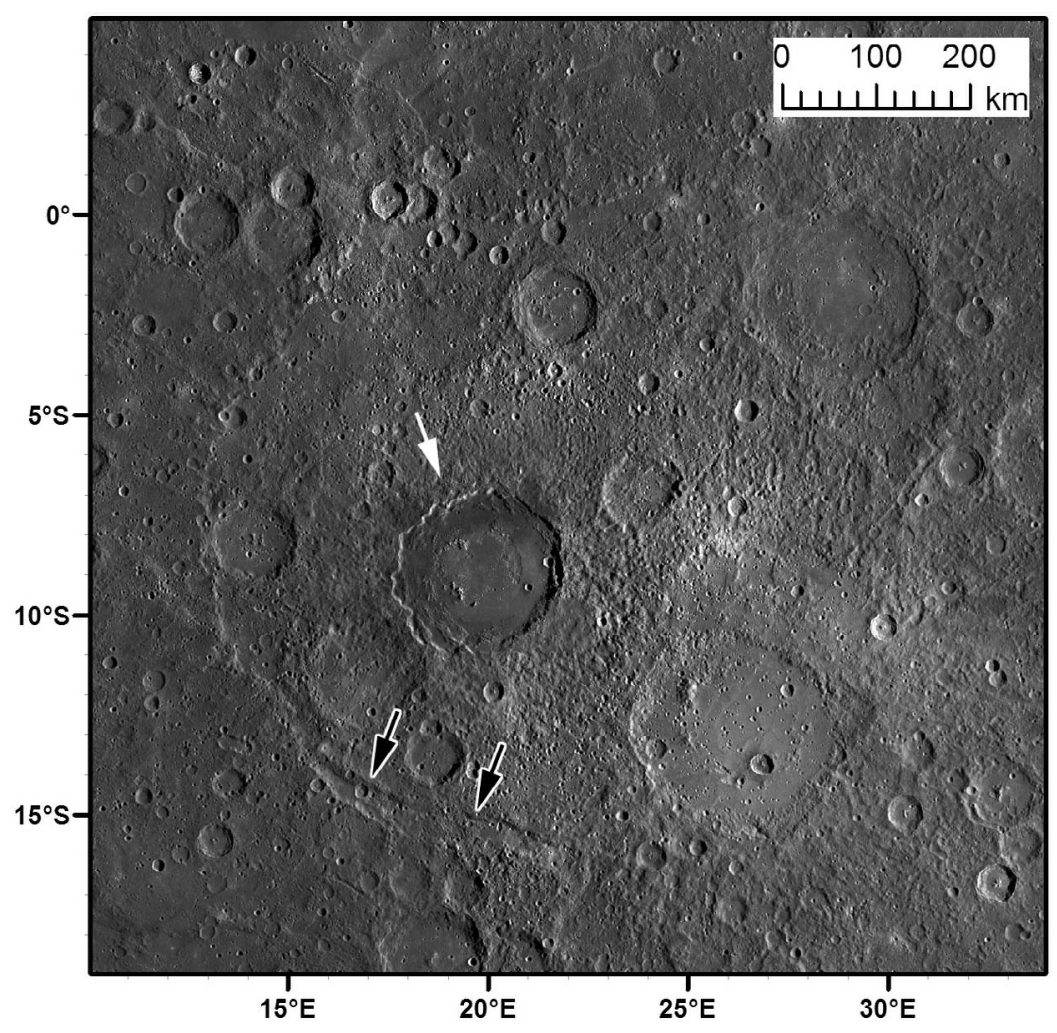

Figure 3. The $730-\mathrm{km}$-diameter basin (b36) centered at $7.6^{\circ} \mathrm{S}, 21.6^{\circ} \mathrm{E}$. The basin is superposed by a number of peak-ring basins, including the fresh peak-ring basin Derain (white arrow). A lobate scarp is apparent near the southern rim of the basin (black arrows).

(black arrows in Figure 3). These scarps are similar to lowrelief scarps that have been recognized within Beethoven [André et al., 2005; Preusker et al., 2012]. Localization of contractional deformation involving material thrust away from the basin center is common within large basins on Mercury [Watters et al., 2012].

\subsubsection{The 470-km-Diameter Basin (b33) at $72.9^{\circ} \mathrm{S}$, $149.9^{\circ} \mathrm{E}$}

[17] A degraded 470-km-diameter basin classified as probable (Figure 4) was observed in near-terminator images acquired during a campaign to evaluate the illumination conditions near Mercury's south pole [e.g., Chabot et al., 2012]. The basin rim is best preserved in its southwestern quadrant (white arrows, Figure 4). The basin is floored by plains that are markedly smoother than the surrounding, more heavily cratered terrain. In some areas, embayment relations are obscured by subsequently formed secondary crater chains (Figure 4; two white arrows on the left), but many distinctive volcanic embayment relationships [see Head et al., 2011] are observed (Figure 4; two white arrows on the right). At least two segments of a prominent lobate scarp are localized along the eastern and southern basin rim (black arrows, Figure 4), where these interior plains have been thrust toward the rim. This lobate scarp crosscuts and deforms craters that postdate the interior plains, indicating that contractional deformation occurred after smooth plains emplacement and that the feature cannot be a thick flow front.

\subsubsection{The 470-km-Diameter Basin (b38) at $13.4^{\circ} \mathrm{S}$, $-6.6^{\circ} \mathrm{E}$}

[18] A relatively well-preserved basin, in the certain category and $470 \mathrm{~km}$ in diameter, is centered at $13.4^{\circ} \mathrm{S},-6.6^{\circ} \mathrm{E}$ (Figure 5). To its north, northeast, and east this basin has prominent radial troughs (white arrow, Figure 5), interpreted as sculptured ejecta, with widths of $20-25 \mathrm{~km}$ and lengths of $100-200 \mathrm{~km}$. The basin rim is non-circular in its eastern sector and has quasi-linear segments that lead to nearperpendicular corners, similar to those in the eastern rim of Beethoven. Within $100 \mathrm{~km}$ of the basin center, young smooth plains embay post-basin craters and are thus stratigraphically separable from the basin itself. The limited extent of the plains may be a result of their confinement within an interior basin ring, although no clear interior rings are observed.

[19] Several chains of secondary craters $(\sim 10 \mathrm{~km}$ wide) are superposed on the basin interior and are also embayed by the smooth plains. At present, the source of these crater chains is not clear, although the $430-\mathrm{km}$-diameter basin (b37) immediately to its south, discussed below, is a possible candidate. If these crater chains could be attributed to that basin, then the relative stratigraphy of these two basins, which is presently uncertain, could be established.

[20] Outward-facing scarps are present within the basin interior along portions of the rim (black arrow, Figure 5), particularly on its southern and eastern sides. As with previous examples, basin interior material has been thrust toward the rim. The scarp on the eastern margin of the basin 


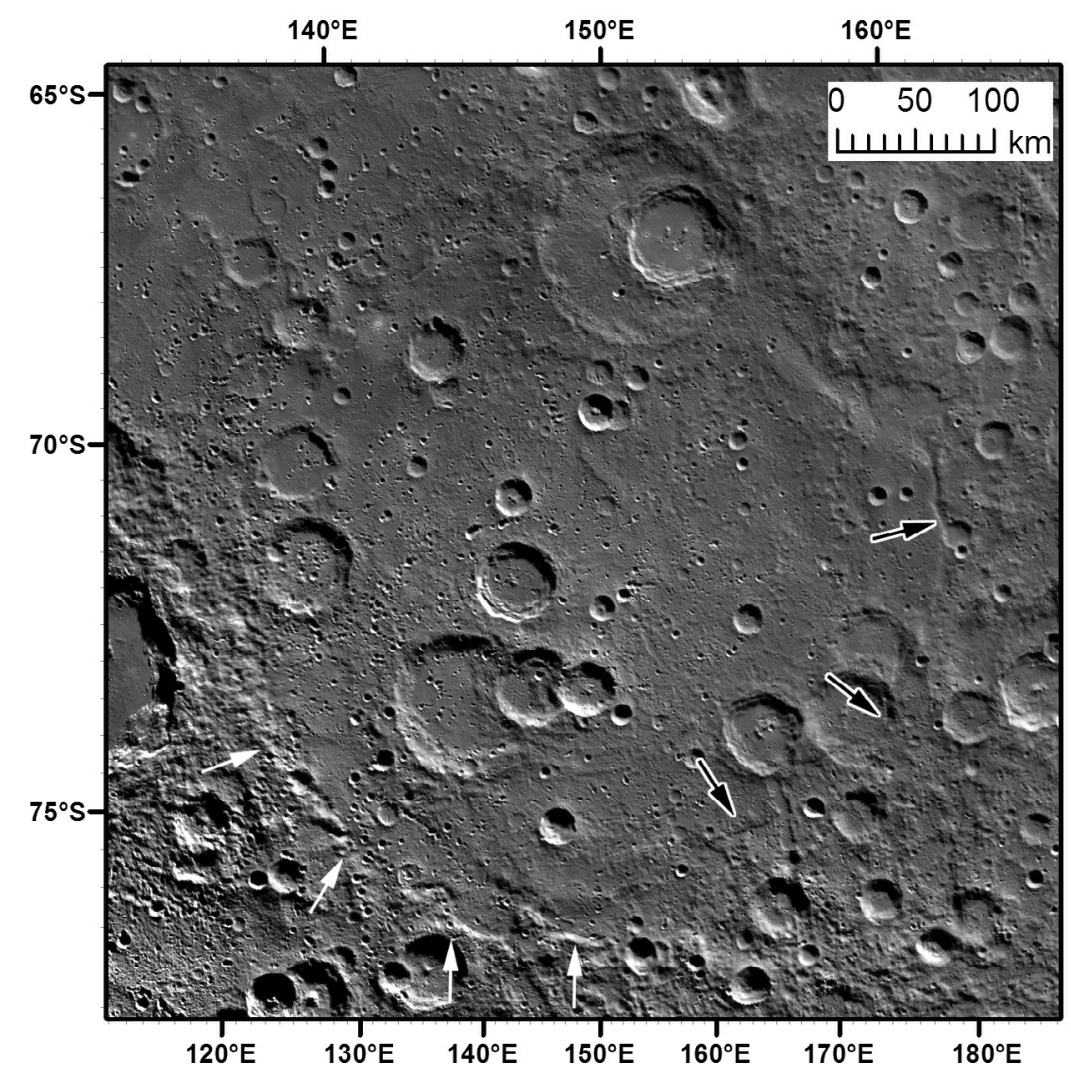

Figure 4. The 470-km-diameter basin (b33) centered at $72.9^{\circ} \mathrm{S}, 149.9^{\circ} \mathrm{E}$. This is a degraded basin at high latitudes in the southern hemisphere. The most prominent portion of the basin rim is to the south and west (white arrows); a prominent lobate scarp is to the south and east (black arrows).

is notable because it deforms two relatively fresh large craters, $20 \mathrm{~km}$ and $40 \mathrm{~km}$ in diameter. This relation implies that the most recent episode of thrust faulting in this location occurred well after basin formation and the emplacement of the smooth plains, consistent with relationships between lobate scarps and plains observed in other large basins and elsewhere in this region.

\subsubsection{The $430-\mathrm{km}$-Diameter Basin $(\mathrm{b37})$ at $27.3^{\circ} \mathrm{S}$,} $-3.2^{\circ} \mathrm{E}$

[21] Just east of the hilly and lineated terrain [Murray et al., 1974], and immediately to the south of the previous example, is a $430-\mathrm{km}$-diameter basin in the certain category that has two large craters $(90 \mathrm{~km}$ and $145 \mathrm{~km}$ ) superposed on its rim (Figure 6). Both of these superposed craters have smooth plains on their floor, and the basin itself has smooth plains in its interior that completely bury its eastern rim. The eastern rim may have been particularly susceptible to burial because this basin is superposed on a degraded large basin to its east (b34 in Table 1); the presence of the older basin may have contributed to lower original rim relief to the east. Several craters in excess of $30 \mathrm{~km}$ diameter have been superposed on the basin floor and then flooded in their interiors and embayed on their exteriors. These relations suggest that volcanic plains emplacement interior to the basin continued long after the basin formed. No interior rings are observed. Degraded basin ejecta deposits are observed to the northeast of the basin and to its south.

[22] One of the more remarkable features associated with this basin is a lobate scarp more than $200 \mathrm{~km}$ long that completely cuts through the smooth floor of the $145-\mathrm{km}$ diameter crater on its western rim (arrow, Figure 6). The location of this scarp appears to have been controlled by the pre-existing basin structure and follows what would have been the basin rim prior to formation of the $145-\mathrm{km}$ diameter crater. The fact that this large, outward-facing scarp traces the basin rim despite its location within a younger, large crater suggests that the fault follows a weak zone along the original basin floor and, thus, that it may extend to substantial depth (several tens of kilometers), consistent with models for the depth extent of faulting beneath other largescale lobate scarps [Watters et al., 2002; Nimmo and Watters, 2004]. A similar relationship between a scarp, basin, and younger crater is found in the 130-km-diameter Sayat-Nova crater superposed on the rim of Beethoven basin [Preusker et al., 2012].

\subsubsection{The 310-km-Diameter Basin (b40) at $6.5^{\circ} \mathrm{N}$, $134.8^{\circ} \mathrm{E}$}

[23] An example of one of the most heavily modified of the newly identified probable basins is a $310-\mathrm{km}$-diameter structure located $\sim 500 \mathrm{~km}$ southwest of the rim of Caloris (Figure 7). Very little of the rim remains intact, except for a small segment on its southern edge. Presently, the basin is outlined by a partial wrinkle-ridge ring. Many other examples of wrinkle-ridge rings have been recognized on Mercury [e.g., Head et al., 2008, 2011; Klimczak et al., 2012], but most are smaller in scale. This basin predates Caloris, since material inside its rim is sculptured by Caloris ejecta [e.g., Fassett et al., 2009] (Figure 7, black arrow). The plains 


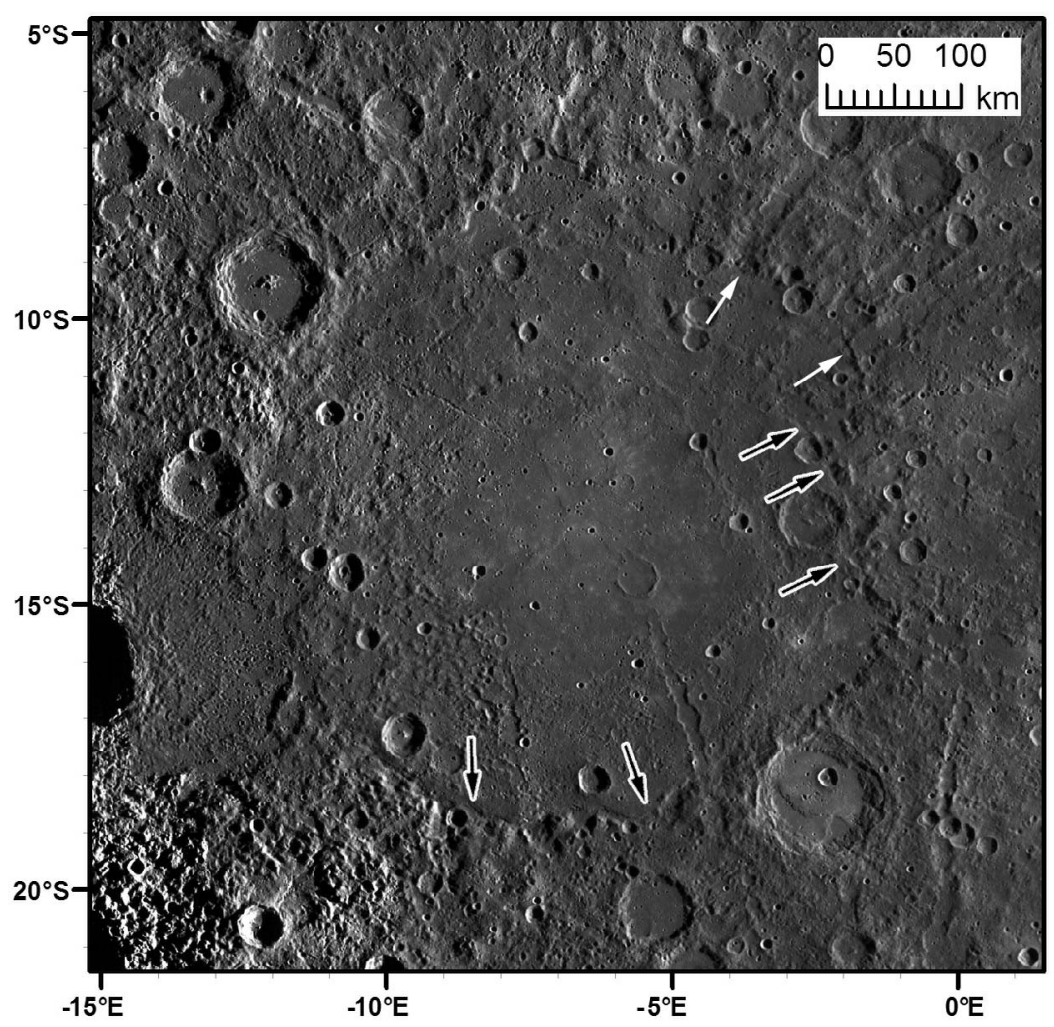

Figure 5. The $470-\mathrm{km}$-diameter basin (b38) centered at $13.4^{\circ} \mathrm{S},-6.6^{\circ} \mathrm{E}$. This relatively well-preserved basin has prominent radial troughs or basin sculpture to its north, northeast, and east (white arrows) and is floored by smooth plains. A lobate scarp on the basin's eastern margin (black arrows) deforms two relatively fresh large craters, $20 \mathrm{~km}$ and $40 \mathrm{~km}$ in diameter; another scarp is seen on the southern edge of the basin (black arrows). There are several secondary crater chains superposed on the basin floor.

that presently bury the basin, however, are a portion of the broad expanse of smooth plains exterior to and younger than the Caloris basin. Given the burial and modification state of this basin, it is not surprising that no interior rings or sculptured ejecta outside the basin are observed.

\subsection{Previously Proposed Basins Not Confirmed by New Data}

[24] Previously proposed basins that are uncertain and remain unverified by MESSENGER data are listed in Table 2, along with additional features in the same category seen for the first time in MESSENGER images. Some of these features remain possible, though uncertain, candidates for degraded basins (e.g., Mena-Theophanes). However, none of the proposed basins listed in Table 2 display strong evidence for a basin interpretation in MESSENGER orbital data. Most were suggested on the basis of inferred arcs linking tectonic features such as ridges and scarps, which are ubiquitous on Mercury's surface; fitting arcs or circles to these tectonic features thus has the potential to lead to false positives. As an example, some candidate basins (e.g., b22, b25) proposed on the basis of near-terminator images obtained during the MESSENGER flybys now appear less likely to be impact features. Orbital data have revealed that the postulated rims of these basins are tectonic features, rather than basin rim segments, undercutting the original interpretation.
[25] Several workers have argued for the existence of highly degraded basins on the Moon and Mars [e.g., Frey, 2011]. As with the lunar examples, many of the candidate basins on Mercury classified here as suggested but unverified are likely to be ancient (pre-Tolstojan) if an impact origin is ultimately shown to be correct. Basins in this category are predominantly located in heavily cratered terrain and have virtually no topographic expression where data are available. Stratigraphy would also suggest that, if they are basins, they would be among the oldest such features in their region. If empirical saturation were reached during the period of heavy bombardment on the Moon and Mercury, as has been argued [e.g., Fassett et al., 2011], then a population of craters and basins degraded to and beyond the limits of recognition is an expected consequence. For this reason, some of the features we classify as suggested but unverified may in fact be the most degraded part of the recognized basin population on the surface of Mercury.

[26] On the other hand, some of the features we have included in this category are not basins. A candidate basin 1000-2000 km in scale named "Skinakas" or "Basin S" was suggested by Ksanfomality [2004, 2008, 2009] and Ksanfomality and Sprague [2007] on the basis of telescopic images of Mercury, as was a nearby feature nicknamed "Medallion" [Ksanfomality, 2008, 2009]. MESSENGER images of these proposed basins have been thoroughly 


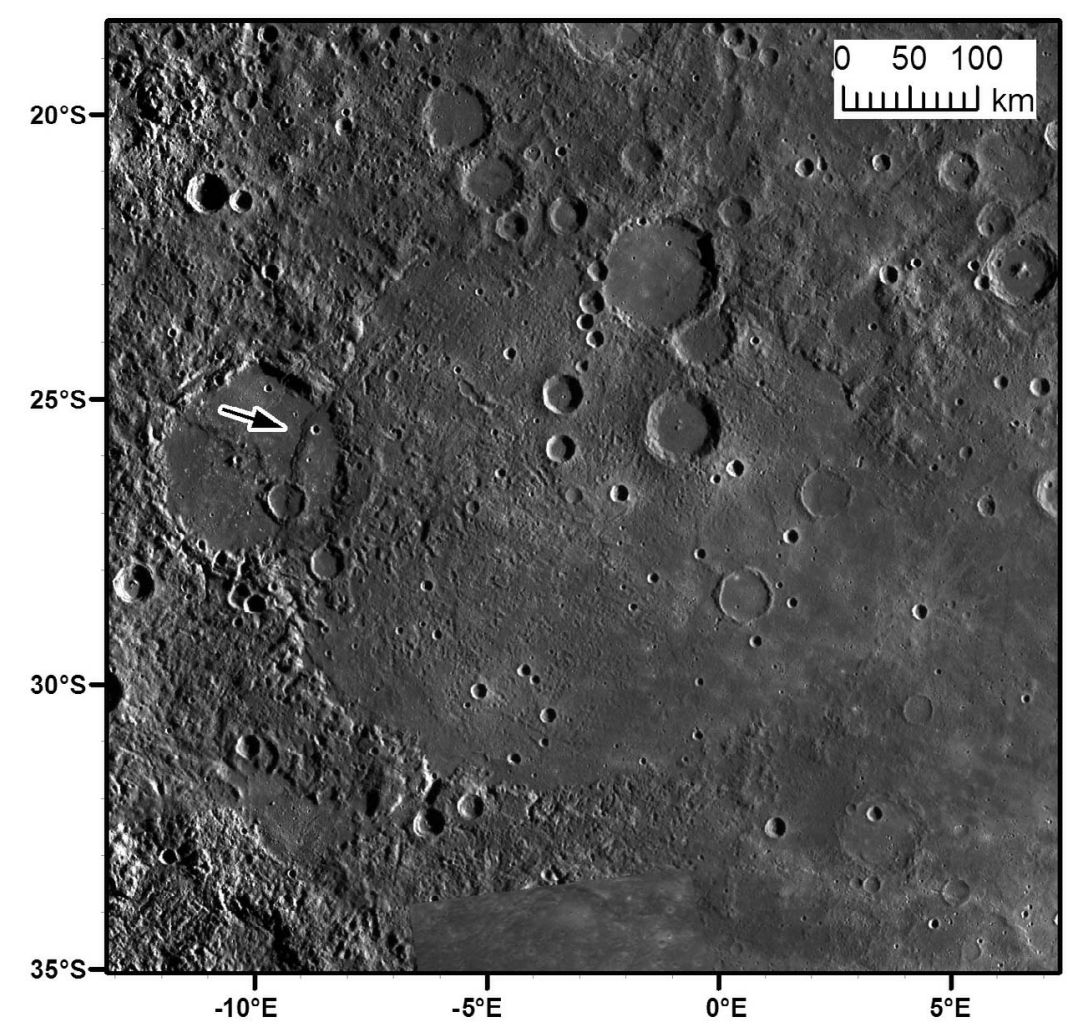

Figure 6. The $430-\mathrm{km}$-diameter basin (b37) centered at $27.3^{\circ} \mathrm{S},-3.2^{\circ} \mathrm{E}$. This basin has two large craters superposed on its northern and western rim. Both the basin and these superposed craters have smooth plains on their floors. The crater superposed on the western rim has a lobate scarp (black arrow) in its interior that appears to have been controlled by the earlier basin structure.

evaluated, and no features suggestive of basins are seen at the proposed locations.

[27] Comparison of telescopic images of Mercury with both Mariner 10 and MESSENGER data does suggest that albedo features of approximately $\sim 100-200 \mathrm{~km}$ extent and larger are resolvable under prime viewing conditions. In particular, the high-reflectance deposit northeast of Rachmaninoff ( $\sim 150 \mathrm{~km}$ in extent) was clearly imaged by Dantowitz et al. [2000]. The classical albedo feature Solitudo Aphrodites [Dollfus et al., 1978] may have contributed to the interpretation by Ksanfomality [2004, 2008, 2009] of basin "S." However, features smaller than hundreds of kilometers are not resolved from Earth-based telescopic data. The subtle nature and limited topographic expression of many of the basins described here, as well as the substantial challenges to telescopic imaging of Mercury, underline the difficulty of identifying basins from Earth.

\section{Discussion}

\subsection{Geographic Distribution}

[28] The geographic distribution of basins on Mercury (Figure 1) is non-uniform, a pattern than may reflect differences either in basin formation or regional resurfacing. The eastern hemisphere ( 0 to $\left.180^{\circ} \mathrm{E}\right)$ has fewer mapped basins $(n=14)$ than the western hemisphere $\left(-180^{\circ} \mathrm{E}\right.$ to $\left.0^{\circ} \mathrm{E}\right)$ $(n=32)$. If the impact probability were uniform over the planet, the probability that 32 or more basins out of a total of
46 will be centered in either hemisphere is only $1.1 \%$ (note that this binomial probability calculation neglects the fact that basins are spatially extended objects).

[29] The significant difference in the number of $D \geq$ $300 \mathrm{~km}$ basins seen on the two hemispheres is unlikely to be attributable to observational biases. For instance, nearterminator images of the region from $60^{\circ} \mathrm{E}$ to $120^{\circ} \mathrm{E}$ ideal for the recognition of impact features were obtained during the MESSENGER flybys, yet this longitude range hosts fewer observed basins than any other comparable span of longitudes.

[30] One possible explanation for the dichotomy in the number of observed basins on the two hemispheres is that the impact probability was non-uniform, as would be the case if Mercury were once in synchronous rotation, a situation that can lead to large lateral variations in impact rate [Wieczorek et al., 2011]. The geographic distribution of basins appears consistent with this idea, although additional analysis is necessary to assess the agreement between observations and the expected magnitude of this effect.

[31] Another possible explanation for the hemispheric difference in basin density is that it is a result of differential resurfacing. The distribution of smooth plains that might have buried degraded basins is clearly non-uniform [Denevi et al., 2009], as is the distribution of young terrains as determined by crater density [Fassett et al., 2011]. Heterogeneous resurfacing could potentially help account for the lack of recognized basins in a large region to the 


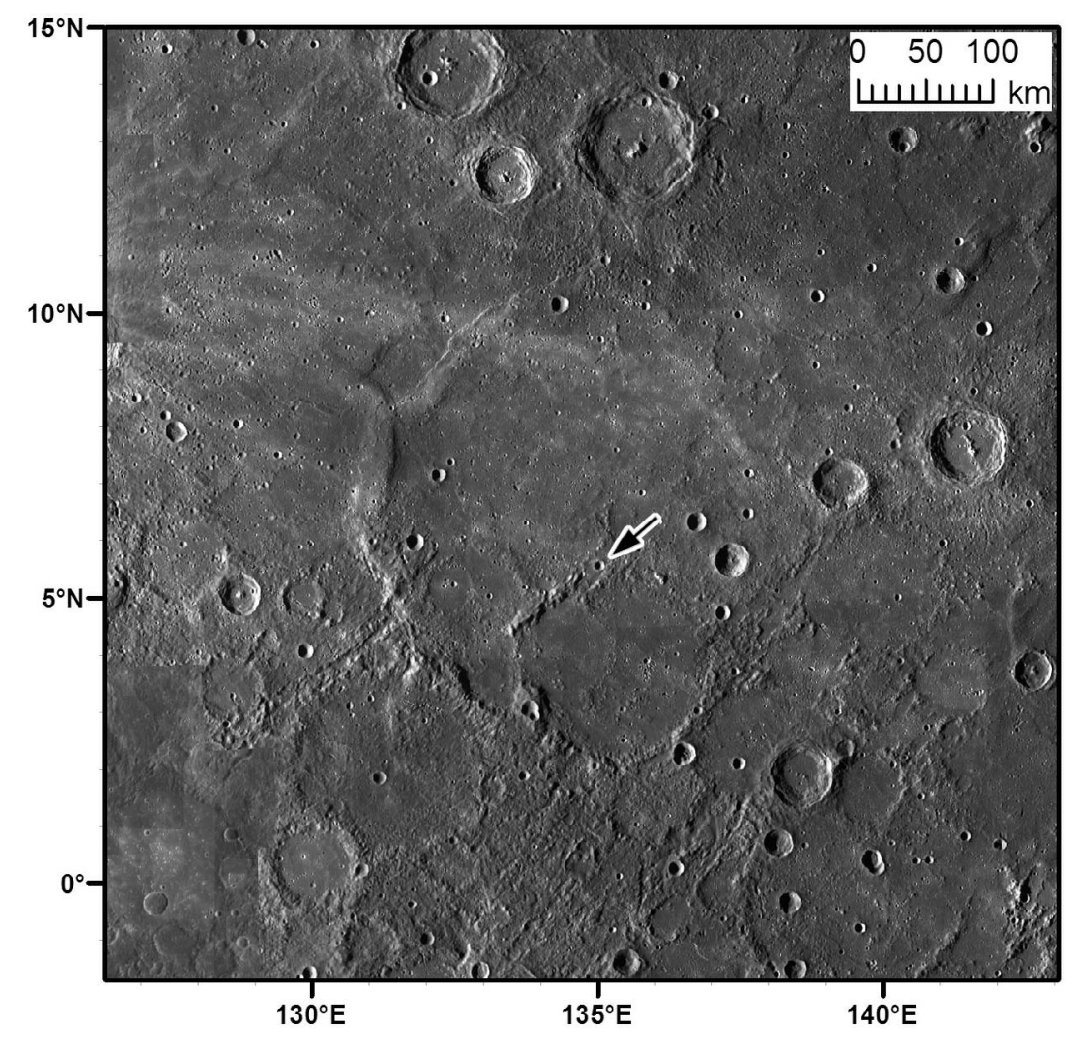

Figure 7. The $310-\mathrm{km}$-diameter basin (b40) centered at $6.5^{\circ} \mathrm{N}, 134.8^{\circ} \mathrm{E}$. This feature is an example of one of the most heavily modified impact basins on Mercury and is exposed here predominantly as a wrinkleridge ring. The basin itself is nearly entirely buried by plains, with the partial exception of its southern rim. Sculptured ejecta deposits from Caloris superposed on massifs in its interior (part of a younger crater rim; black arrow) indicate that this basin predates the Caloris basin.

northwest of Caloris. However, there are broad regions that generally lack both extensive smooth plains and probableto-certain basins (e.g., longitudes $30^{\circ}$ to $70^{\circ} \mathrm{E}$ in the southern hemisphere).

[32] Finally, it is intriguing that the observed hemispheric difference is due to the number of moderate-sized basin $(D=300-500 \mathrm{~km})$, rather than the number of large basins. For $D \geq 500 \mathrm{~km}$, there are 8 basins in the eastern hemisphere and 9 in the western hemisphere. However, because of the small number of features involved, this distribution may be a product of chance rather than a significant difference in the behavior of basins $300-500 \mathrm{~km}$ and $\geq 500 \mathrm{~km}$ in diameter; for example, if the true impact probability on the western hemisphere were twice that of the eastern hemisphere, there is still a $17 \%$ chance that the eastern hemisphere could end up with an allotment of 8 or more basins with $D \geq 500 \mathrm{~km}$ out of a total of 17 .

\subsection{Basin Topography and Gravity}

[33] Topographic data from MLA of Mercury's northern hemisphere [Zuber et al., 2012] reveal that the dynamic range of topography $(9.85 \mathrm{~km})$ is considerably smaller than that of the Moon $(19.9 \mathrm{~km})$ and Mars $(30 \mathrm{~km})$. Zuber et al. [2012] suggested that part of this difference could be due to the shallow core-mantle boundary of Mercury [Smith et al., 2012] and the possible influence of viscous flow in the mantle and the consequent relaxation of the largest crustal structures, such as the basins we consider here [e.g., Zhong and Zuber, 2000; Mohit et al., 2009]. Even the topography of the comparatively well-preserved Caloris basin has been substantially modified [Oberst et al., 2010] by processes that led to portions of its interior now standing higher than its rim [Zuber et al., 2012].

[34] On Mercury, volcanism appears dominated by emplacement of flood lavas, rather than centralized edifice building [Head et al., 2008, 2009, 2011; Wilson and Head, 2008]. Along with the lack of large rift zones, this absence of large edifices may help explain the difference in topographic range. Flood volcanism leads to regional infilling of topographic lows, preferential flooding of crater and basin interiors, and modification of intercrater areas. For example, the contiguous northern volcanic plains on Mercury cover about $6 \%$ of the surface, and very few rims of preexisting craters protrude through this deposit, indicating local lava thicknesses in excess of 1-2 km [Head et al., 2011]. Such widespread, extensive flooding can readily obscure basin topography at a wide range of scales. Indeed, although the north polar region is a broad lowland, there are only a few probable-to-certain basins in this region (Figure 1b), and additional candidate basins in this area are all degraded to the point of ambiguity.

[35] MESSENGER spacecraft tracking data have yielded a model of Mercury's gravity field [Smith et al., 2012]. Prominent positive gravity anomalies in the northern 
hemisphere are collocated with the Caloris basin and a region near Sobkou, but at the current resolution of the gravity field, most positive anomalies are not clearly associated with mapped impact basins. Combination of the gravity field [Smith et al., 2012] and topography [Zuber et al., 2012] permits the modeling of crustal thickness in Mercury's northern hemisphere. The thinnest crust mapped is beneath the northern lowlands at high northern latitudes, but evidence for a large impact basin there that meets our identification criteria is lacking, perhaps due to flooding and obscuration by subsequent impacts and volcanic plains emplacement [e.g., Head et al., 2011]. Evidence for crustal thinning is seen beneath some impact basins, and Caloris, Sobkou, and Budh meet the criteria for mascons on the basis of evidence for a substantially elevated crust-mantle boundary.

\subsection{Multiple Rings}

[36] Multiple (two or more) rings are uncommon in basins $\geq 300 \mathrm{~km}$ in diameter on Mercury. The great majority $(>75 \%)$ of the certain and probable basins we identified have only one physiographically prominent ring that we interpret as the basin rim, often defined by an inward-facing topographic scarp. We typically do not find strong evidence for additional rings, either inward of or exterior to this main topographic rim, for example at the positions suggested by Spudis and Guest [1988].

[37] This lack of multiple rings is clearly different from the situation for basins on the Moon, where $52 \%$ of basins have at least one interior ring. Even the main rims of basins on Mercury are less commonly intact than their counterparts on the Moon. A complete or nearly complete rim that encircles more than $75 \%$ of the basin is found only for $24 \%$ of the basins with $D \geq 300 \mathrm{~km}$ on Mercury, compared with $48 \%$ of the basins of the same size on the Moon. (Both of the lunar measurements given here were obtained for this study with the same criteria that were applied to Mercury).

[38] An example of a basin with an interior ring is Homer, a large peak-ring basin [Baker et al., 2011]. In a few basins, such as Tolstoj and b38 (Figure 5), smooth plains are observed in the central portion of the basin and may be bounded by an interior ring and confined by the resulting basin topography. Likewise, in Beethoven, Rembrandt [Watters et al., 2009a], and Caloris [Fassett et al., 2009], prominent wrinkle ridge rings within the basins may have been localized by the concentration of horizontal compressive stresses over volcanically buried interior basin rings.

[39] The lack of multiple rings in basins greater than $300 \mathrm{~km}$ in diameter on Mercury is surprising, given that peak-ring basins are more common on Mercury than on the Moon or Mars [Baker et al., 2011, 2012]. The reason that peak-ring basins have preserved inner rings, whereas larger basins lack inner rings, may be attributable to differences in basin formation, basin modification, or both. For instance, there is substantial evidence that the proportion of impact melt produced during impact events increases with increasing size [e.g., Cintala and Grieve, 1998], and so impact melt production may serve to obscure basin interior structure and ring development in the largest basins. Moreover, relatively more impact melt is thought to result from the highervelocity impacts on Mercury, compared with the Moon and other terrestrial planets [Gault et al., 1975; Le Feuvre and Wieczorek, 2011].

[40] The interior structure of Mercury is known to differ markedly from that of the Moon [e.g., Smith et al., 2012], and this difference could result in differences in the formation of ring structures, such as additional rings beyond the rim crest and peak ring [e.g., Head, 2010]. For example, loading of the basin rim and its immediate surroundings by ejecta are enhanced on Mercury relative to the Moon, due to the planet's stronger surface gravitational acceleration [Gault et al., 1975]. The combination of this enhanced loading, and the distinct interior and thermal structure of Mercury, could result in early stage viscous, viscoelastic, or viscoplastic relaxation of basins, in contrast to brittle deformation thought to be responsible for the outer ring and "megaterrace" often seen in large lunar basins [e.g., Head, 2010]. Immediately after basin formation, the thermal structure of Mercury may have favored the relaxation of basin topographic relief, including the prominence of basin ring structures [e.g., Mohit et al., 2009], as was commonly the case for early lunar basins [e.g., Baldwin, 1971; Solomon et al., 1982]. Although relaxation by crustal and mantle flow is wavelength-dependent, preferentially favoring the preservation of shorter-wavelength features such as topographic rings, the broad relaxation of topography can enhance the influence of other processes, such as volcanism, in the obliteration of basin structure.

[41] On longer timescales, as described above for specific examples, such processes as the formation of superposed impact craters and basins also serve to obscure basin structure. Moreover, many large basins on Mercury are floored by or covered by plains deposits, and burial of interior rings by volcanism could explain the paucity of interior structures. Extensive burial of basins by volcanism (e.g., Figure 7) may also contribute to the lower percentage of basins on Mercury with a largely intact rim compared with basins on the Moon.

\subsection{Basin Ejecta and Sculpture}

[42] Evidence for radial or sculptured ejecta (e.g., Figure 5) is observed around $26 \%$ of the probable or certain basins on Mercury, a figure close to that of lunar basins in this size range (32\%; assessed for this study). This fraction of basins with preserved sculpture is more similar on Mercury and the Moon than the fraction of basins with wellpreserved rims, an observation suggesting that the interiors of large basins on Mercury may have been more heavily modified than their immediate surroundings.

\subsection{Basin Formation, Volcanism, and Tectonics}

[43] The relationship between basin formation and postbasin volcanism and tectonics provides an important basis for understanding how impact cratering (an exogenic process) and interior (endogenic) processes interact. A few comments related to this topic follow from our survey of the global population of impact basins on Mercury.

[44] First, all of the certain or probable basins larger than $300 \mathrm{~km}$ in diameter show evidence for superposed smooth or intercrater plains that postdate the basins. Basin b36 (Figure 3) has perhaps the least evidence for plains in its interior, in large part due to the numerous superposed craters and peak-ring basins. More extensive plains exposures, as are seen in Figures 4-7, are more common. Not only do 


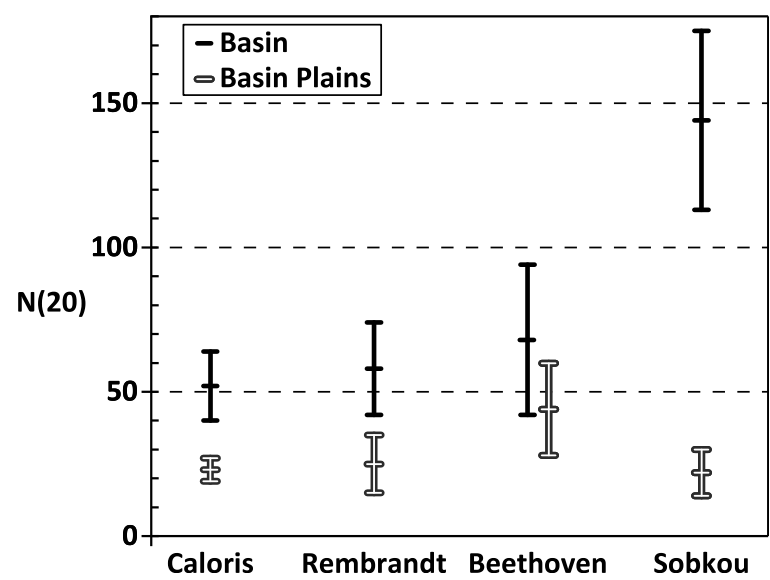

Figure 8. Density $N(20)$ of younger craters greater than or equal to $20 \mathrm{~km}$ in diameter on basin deposits and interior smooth plains at Caloris, Rembrandt, Beethoven, and Sobkou basins. These data illustrate the separation in time that generally exists between basin formation and the last major volcanism within the basins. Errors shown are from counting statistics alone $(\sqrt{ } N / A)$.

most basins appear to be at least partially flooded by plains, but initial observations suggest that plains are preferentially located in and around large impact basins. Verifying this relationship will require more complete geological mapping of the surface of Mercury than has been conducted to date.

[45] Second, some basins, such as Caloris, Rembrandt, Beethoven, and Sobkou, have sufficiently large exposures of both smooth volcanic plains and basin facies that it is possible to derive independent crater densities for the plains and basins. Current estimates for the density $N(20)$ of impact features at least $20 \mathrm{~km}$ in diameter in these four basins are $52 \pm 12,58 \pm 16,68 \pm 26$, and $144 \pm 31$, respectively. In contrast, the plains within these basins have $N(20)$ values of $23 \pm 4,25 \pm 10,44 \pm 16$, and $22 \pm 8$, respectively (Figure 8). Thus, the plains are generally appreciably younger than the basins in which they are deposited. This observation provides strong evidence that these interior plains must be volcanic rather than impact melt or ejecta, as has been demonstrated elsewhere on Mercury [e.g., Head et al., 2008, 2009, 2011]. It also suggests that plains emplacement is unlikely to be solely associated with pressure-release melting immediately following the impact [cf. Elkins-Tanton et al., 2004].

[46] Third, on the basis of examination of the basins cataloged in this study, post-basin tectonic modification was important as well. Many basins experienced large-scale deformation, mainly along thrust faults that localized near or at the basin margins and have hanging walls that consist of units interior to the basins (Figures 3-6). The thrust faults underlying the observed lobate scarps commonly crosscut younger craters, or deform smooth plains, suggesting that most outward-facing scarps at the margin of basins are tectonic in origin rather than preserved volcanic flow fronts, although specific exceptions may exist [see Head et al., 2011, Figure 3]. The presence of these prominent scarps along or near the basin rim suggests that the localization of contractional deformation on Mercury is favored along weak zones that follow the rims and floors of large impact structures. Further, the age relationships between scarps and both young craters and smooth plains indicate that at least some portion of large-scale thrust faulting postdated volcanic plains emplacement.

[47] Wrinkle ridges that are found in smooth plains units also appear to be affected by pre-existing basins (e.g., Figure 7), as is common for smaller craters. In a few instances, evidence of extensional tectonic features is observed in some large basins, such as Caloris [Watters et al., 2005] and Rembrandt [Watters et al., 2009a], although extension is less common than compression, as has been noted elsewhere [e.g., Watters et al., 2009b].

\subsection{Spatial Density of Basins on Mercury and the Moon}

[48] A substantially lower density of large $(D \geq 500 \mathrm{~km})$ certain or probable basins is observed on Mercury than the Moon. Indeed, the basin population on Mercury would be more similar to the lunar population if all pre-Nectarian basins on the Moon were excluded. There are three broad categories of hypotheses that might explain this difference: (1) An observational effect: The lower density on Mercury might simply be a result of the type or quality of data available for Mercury compared with data for the Moon. (2) A formational effect: Differences in the basin formation process on the two planetary bodies, for instance, might be expressed as a lower density of the largest basins on Mercury (e.g., if growth of the basin cavity or outer ring formation were inhibited or rapidly modified during basin formation on Mercury). Alternatively, a different population of large impactors affecting Mercury from those impacting the Moon might result in fewer large basins. Or, if basins on Mercury form with less initial topographic relief than on the Moon, it may make them more susceptible to modification and obscuration. (3) A later-stage modification effect: After formation, large basins on Mercury might simply have been modified and degraded more efficiently. Relaxation of large basins may have occurred by crustal and mantle flow, followed by emplacement of plains, either due to widespread volcanism unrelated to basin formation, or as a result of volcanism triggered by basin formation.

[49] It is unlikely that the difference in the density of large basins can be solely an observational effect. MESSENGER data have provided a global image mosaic with conditions suitable for recognition of impact basins over most of the surface of Mercury. On the basis of data from Mariner 10, the three MESSENGER flybys, and MESSENGER orbital observations, much of the surface has been imaged at multiple illumination geometries. Topography from MLA [Zuber et al., 2012] and stereo images [Preusker et al., 2011, 2012] provide additional data for recognizing basins.

[50] For Mercury to have a lunar-like density of probableto-certain $D \geq 500 \mathrm{~km}$ basins would require an addition of approximately ten more features of this size on Mercury. Although a few additional candidates of this size are recognized, the candidate basins in Table 2 are at best uncertain, and most are unlikely to be impact structures. Moreover, the density of probable-to-certain lunar basins given here is conservative, and the Moon also has numerous candidate basins of this size [see, e.g., Frey, 2011] that are similar to the basins in the suggested but unverified class here. Applying a different threshold for basin recognition is thus unlikely to 
close the observed difference between the two planetary bodies.

[51] An explanation for this difference that focuses on basin formation processes is more promising. As described above, there are known differences in parameters that affect crater formation on the Moon and Mercury, such as impact velocity, surface gravitational acceleration, and planetary interior structure, all of which can affect crater growth [e.g., Schultz, 1988], collapse [e.g., Head, 2010], and early modification. Exploring this explanation would require additional modeling of the basin formation process, which could help better to constrain this idea. One option is that the outward growth of basins is inhibited on Mercury compared with the Moon, so that formation of rings equivalent to the Cordillera ring surrounding the lunar Orientale basin [Head, $1974,2010]$ is less likely. If this were the case, such an effect might lead to a lower density of very large basins on Mercury than the Moon. For example, if ten of the basins in the 300-500 km diameter range on Mercury had developed a distinctive outer topographic ring that would alter our interpretation of the overall basin size, the discrepancy between the Moon and Mercury (Figure 2) would be reduced or erased without substantially affecting the statistics at diameters less than $D=500 \mathrm{~km}$. Currently it is thought that Mercury and the Moon had the same early impactor populations, on the basis of the similarity in the shape of their crater size-frequency distributions [e.g., Strom et al., 2008, 2011; Fassett et al., 2011]. Although vulcanoids could be a distinct reservoir of impactors for Mercury [e.g., Leake et al., 1987], it is not clear how this extra reservoir of impacting objects would yield a situation in which Mercury has fewer large basins than the Moon, particularly with a similar size-frequency distribution and similar density of smaller impact features.

[52] Thus, as an explanation of the difference in density of large basins between Mercury and the Moon, we favor a combination of factors, including (1) less ready development of an outer basin ring on Mercury, (2) more extensive early modification of topographic relief for basins on Mercury, and (3) more extensive later modification of the largest basins on Mercury by interior volcanism. Specifically, it appears that volcanism and deformation were more important during the early history of Mercury than during comparable periods on the Moon, and thus more efficient at obscuring and/or obliterating large basins on Mercury than on the lunar surface. On the Moon as well as on Mercury, densities of heavily cratered surfaces are consistent with their having been cratered to saturation equilibrium [e.g., Fassett et al., 2011, and references therein]. However, if another process such as volcanism were important for obliterating basins, the expected equilibrium population of basins would be at a lower density than from crater saturation alone [see, e.g., Chapman and Jones, 1977]. In the case of Mercury, because impact features in the diameter range $D \sim 128-512 \mathrm{~km}$ have the similar density as on the Moon, modification processes would have to affect larger basins most strongly. Differences in basin collapse stages [e.g., Head, 2010] could make large impact basins appear initially smaller and/or less prominent, relaxation by crustal and mantle flow [e.g., Mohit et al., 2009] could preferentially modify larger features, and volcanism linked to the formation of the largest basins [e.g., Roberts and Barnouin, 2012] could help account for these observations. All basins on Mercury $\geq 300 \mathrm{~km}$ in diameter, including features 300 $500 \mathrm{~km}$ in diameter, show evidence for being at least partially superposed by younger plains, and basins on Mercury have less well-preserved rims and interior rings than those on the Moon. These characteristics point to earlier large basins having been formed, degraded, and buried beyond the point that they can be readily recognized.

\section{Conclusions}

[53] MESSENGER observations have been used to map and characterize large impact basins on Mercury's surface and to test the existence of previously suggested basins. Our data suggest that there are fewer certain or probable impact basins per unit area on Mercury than on the Moon for basins with diameters larger than $500 \mathrm{~km}$. The basins that are observed on Mercury appear qualitatively more degraded than those on the Moon, with less likelihood to have intact rims or interior rings. These data suggest that initial basin formation processes and early modification processes were different on the two bodies. Moreover, volcanism and other geological processes that degrade large basins over longer timescales were more important on Mercury than on the Moon during the first billion years of solar system history.

[54] Acknowledgments. The Integrated Software for Imagers and Spectrometers (ISIS) software package of the United States Geological Survey was used for data processing in this study. We thank Thomas Kneissl for developing and sharing the CraterTools extension to ArcMap. Mapping by Seth Kadish from MESSENGER flyby data helped contribute to this analysis. Reviews by Ken Tanaka and an anonymous reviewer improved this manuscript. The MESSENGER project is supported by NASA Discovery program through contracts to The Johns Hopkins Applied Physics Laboratory (NAS5-97271) and the Carnegie Institution of Washington (NASW-00002).

\section{References}

André, S. L., T. R. Watters, and M. S. Robinson (2005), The long wavelength topography of Beethoven and Tolstoj basins, Mercury, Geophys. Res. Lett., 32, L21202, doi:10.1029/2005GL023627.

Baker, D. M. H., J. W. Head, S. C. Schon, C. M. Ernst, L. M. Prockter, S. L. Murchie, B. W. Denevi, S. C. Solomon, and R. G. Strom (2011), The transition from complex crater to peak-ring basin on Mercury: New observations from MESSENGER flyby data and constraints on basin formation models, Planet. Space Sci., 59, 1932-1948, doi:10.1016/j. pss.2011.05.010.

Baker, D. M. H., et al. (2012), New morphometric measurements of peakring basins on Mercury and the Moon: Results from the Mercury Laser Altimeter and Lunar Orbiter Laser Altimeter, Lunar Planet. Sci., XLIII, Abstract 1238 .

Baldwin, R. B. (1971), The question of isostasy on the Moon, Phys. Earth Planet. Inter., 4, 167-179, doi:10.1016/0031-9201(71)90036-7.

Basaltic Volcanism Study Project (1981), Basaltic Volcanism on the Terrestrial Planets, 1286 pp., Pergamon Press, New York.

Blewett, D. T., et al. (2011), Hollows on Mercury: MESSENGER evidence for geologically recent volatile-related activity, Science, 333, 1856-1859, doi:10.1126/science.1211681.

Butler, B. J., D. O. Muhleman, and M. A. Slade (1993), Mercury: Full-disk radar images and the detection and stability of ice at the north pole, J. Geophys. Res., 98, 15,003-15,023, doi:10.1029/93JE01581.

Cavanaugh, J. F., et al. (2007), The Mercury Laser Altimeter instrument for the MESSENGER mission, Space Sci. Rev., 131, 451-479, doi:10.1007/ s11214-007-9273-4.

Chabot, N. L., C. M. Ernst, B. W. Denevi, J. K. Harmon, S. L. Murchie, D. T. Blewett, S. C. Solomon, and E. D. Zhong (2012), Areas of permanent shadow in Mercury's south polar region, Geophys. Res. Lett., 39, L09204, doi:10.1029/2012GL051526.

Chapman, C. R., and K. L. Jones (1977), Cratering and obliteration history of Mars, Annu. Rev. Earth Planet. Sci., 5, 515-538, doi:10.1146/annurev. ea.05.050177.002503 
Chapman, C. R., W. J. Merline, L. R. Ostrach, Z. Xiao, S. C. Solomon, J. W. Head, and J. L. Whitten (2011), Statistics of morphologies of small primary and secondary craters on Mercury's northern plains, Geol. Soc. Am. Abstr. Programs, 43(5), 359.

Cintala, M. J., and R. A. F. Grieve (1998), Scaling impact melting and crater dimensions: Implications for the lunar cratering record, Meteorit. Planet. Sci., 33, 889-912, doi:10.1111/j.1945-5100.1998.tb01695.x.

Crater Analysis Techniques Working Group (1978), Standard techniques for presentation and analysis of crater size-frequency data, NASA Tech. Memo., NASA TM-79730, 24 pp.

Dantowitz, R. F., S. W. Teare, and M. J. Kozubal (2000), Ground-based high-resolution imaging of Mercury, Astron. J., 119, 2455-2457, doi:10.1086/301328.

Denevi, B. W., et al. (2009), The evolution of Mercury's crust: A global perspective from MESSENGER, Science, 324, 613-618, doi:10.1126/ science. 1172226

Dollfus, A., C. R. Chapman, M. E. Davies, O. Gingerich, R. Goldstein, J. Guest, D. Morrison, and B. A. Smith (1978), IAU Nomenclature for albedo features on the planet Mercury, Icarus, 34, 210-214.

Elkins-Tanton, L. T., B. H. Hager, and T. L. Grove (2004), Magmatic effects of the lunar late heavy bombardment, Earth Planet. Sci. Lett. 222, 17-27, doi:10.1016/j.eps1.2004.02.017.

Fassett, C. I., J. W. Head, D. T. Blewett, C. R. Chapman, J. L. Dickson, S. L. Murchie, S. C. Solomon, and T. R. Watters (2009), Caloris impact basin: Exterior geomorphology, stratigraphy, morphometry, radial sculpture, and smooth plains deposits, Earth Planet. Sci. Lett., 285, 297-308, doi:10.1016/j.eps1.2009.05.022.

Fassett, C. I., S. J. Kadish, J. W. Head, S. C. Solomon, and R. G. Strom (2011), The global population of large craters on Mercury and comparison with the Moon, Geophys. Res. Lett., 38, L10202, doi:10.1029/ 2011 GL047294.

Fassett, C. I., J. W. Head, S. J. Kadish, E. Mazarico, G. A. Neumann, D. E. Smith, and M. T. Zuber (2012), Lunar impact basins: Stratigraphy, sequence and ages from superposed impact crater populations measured from Lunar Orbiter Laser Altimeter (LOLA) data, J. Geophys. Res., 117, E00H06, doi:10.1029/2011JE003951.

Frey, H. (2011), Previously unknown large impact basins on the Moon: Implications for lunar stratigraphy, Spec. Pap. Geol. Soc. Am., 477, 53-75, doi:10.1130/2011.2477(02).

Frey, H., and B. L. Lowry (1979), Large impact basins on Mercury and relative crater production rates, Proc. Lunar Planet. Sci. Conf., 10th, 2669-2687.

Gault, D. E., J. E. Guest, J. B. Murray, D. Dzurisin, and M. C. Malin (1975), Some comparisons of impact craters on Mercury and the Moon, J. Geophys. Res., 80, 2444-2460, doi:10.1029/JB080i017p02444.

Hawkins, S. E., III, et al. (2007), The Mercury Dual Imaging System on the MESSENGER spacecraft, Space Sci. Rev., 131, 247-338, doi:10.1007/ s11214-007-9266-3

Head, J. W. (1974), Orientale multi-ringed basin interior and implications for the petrogenesis of lunar highland samples, Moon, 11, 327-356, doi:10.1007/BF00589168.

Head, J. W. (2010), Transition from complex craters to multi-ringed basins on terrestrial planetary bodies: Scale-dependent role of the expanding melt cavity and progressive interaction with the displaced zone, Geophys. Res. Lett., 37, L02203, doi:10.1029/2009GL041790.

Head, J. W., et al. (2008), Volcanism on Mercury: Evidence from the first MESSENGER flyby, Science, 321, 69-72, doi:10.1126/science.1159256.

Head, J. W., et al. (2009), Volcanism on Mercury: Evidence from the first MESSENGER flyby for extrusive and explosive activity and the volcanic origin of plains, Earth Planet. Sci. Lett., 285, 227-242, doi:10.1016 j.epsl.2009.03.007.

Head, J. W., et al. (2011), Flood volcanism in the northern high latitudes of Mercury revealed by MESSENGER, Science, 333, 1853-1856, doi:10.1126/science. 1211997.

Klimczak, C., T. R. Watters, C. M. Ernst, A. M. Freed, P. K. Byrne, S. C. Solomon, D. M. Blair, and J. W. Head (2012), Deformation associated with ghost craters and basins in volcanic smooth plains on Mercury: Strain analysis and implications for plains evolution, J. Geophys. Res. 117, E00L03, doi:10.1029/2012JE004100.

Kneissl, T., S. van Gasselt, and G. Neukum (2011), Map-projectionindependent crater size-frequency determination in GIS environmentsnew software tool for ArcGIS, Planet. Space Sci., 59, 1243-1254, doi:10.1016/j.pss.2010.03.015.

Ksanfomality, L. V. (2004), A huge basin in the unknown portion of Mercury in the $250^{\circ}-290^{\circ} \mathrm{W}$ longitude range, Sol. Syst. Res., 38, 21-27, doi:10.1023/B:SOLS.0000015152.00598.ed.

Ksanfomality, L. V. (2008), The surface of Mercury from ground-based astronomical observations, Sol. Syst. Res., 42, 451-472, doi:10.1134/ S0038094608060014
Ksanfomality, L. V. (2009), The surface of Mercury in the $210-350^{\circ} \mathrm{W}$ longitude range, Icarus, 200, 367-373, doi:10.1016/j.icarus.2008.12.007.

Ksanfomality, L. V. (2011), Study of the unknown hemisphere of Mercury by ground-based astronomical facilities, Sol. Syst. Res., 45, 281-303, doi:10.1134/S0038094611040034

Ksanfomality, L. V., and A. L. Sprague (2007), New images of Mercury's surface from $210^{\circ}$ to $290^{\circ} \mathrm{W}$ longitudes with implications for Mercury's global asymmetry, Icarus, 188, 271-287, doi:10.1016/j.icarus.2006. 12.009.

Leake, M. A., C. R. Chapman, S. J. Weidenschilling, D. R. Davis, and R. Greenberg (1987), The chronology of Mercury's geological and geophysical evolution: The vulcanoid hypothesis, Icarus, 71, 350-375, doi:10.1016/0019-1035(87)90034-0.

Le Feuvre, M., and M. A. Wieczorek (2011), Nonuniform cratering of the Moon and a revised crater chronology of the inner solar system, Icarus, 214, 1-20, doi:10.1016/j.icarus.2011.03.010.

Malin, M. C. (1976), Comparison of large crater and multi-ringed basin populations on Mars, Mercury, and the Moon, Proc. Lunar Plan. Sci. Conf., 7th, 3589-3602.

Mohit, P. S., C. L. Johnson, O. Barnouin-Jha, M. T. Zuber, and S. C. Solomon (2009), Shallow basins on Mercury: Evidence of relaxation?, Earth Planet. Sci. Lett., 285, 355-363, doi:10.1016/j.eps1.2009.04.023. Murray, B. C., M. J. S. Belton, G. E. Danielson, M. E. Davies, D. E. Gault, B. Hapke, B. O'Leary, R. G. Strom, V. Suomi, and N. Trask (1974), Mercury's surface: Preliminary description and interpretation from Mariner 10 pictures, Science, 185, 169-179, doi:10.1126/science.185.4146.169.

Nimmo, F., and T. R. Watters (2004), Depth of faulting on Mercury: Implications for heat flux and crustal and effective elastic thickness, Geophys. Res. Lett., 31, L02701, doi:10.1029/2003GL018847.

Oberst, J., F. Preusker, R. J. Phillips, T. R. Watters, J. W. Head, M. T. Zuber, and S. C. Solomon (2010), The morphology of Mercury's Caloris basin as seen in MESSENGER stereo topographic models, Icarus, 209 , 230-238, doi:10.1016/j.icarus.2010.03.009

Ostrach, L. R., C. R. Chapman, C. I. Fassett, J. W. Head, W. J. Merline, M. S. Robinson, S. C. Solomon, R. G. Strom, and Z. Xiao (2011) Crater statistics for the northern polar region of Mercury derived from MESSENGER orbital data, Geol. Soc. Am. Abstr. Programs, 43(5), 360

Preusker, F., J. Oberst, J. W. Head, T. R. Watters, M. S. Robinson, M. T. Zuber, and S. C. Solomon (2011), Stereo topographic models of Mercury after three MESSENGER flybys, Planet. Space Sci., 59, 1910-1917, doi:10.1016/j.pss.2011.07.005.

Preusker, F., J. Oberst, D. T. Blewett, K. Gwinner, J. W. Head, S. L. Murchie, M. S. Robinson, T. R. Watters, M. T. Zuber, and S. C. Solomon (2012), Topography of Mercury from stereo images: First samples from MESSENGER orbital mapping, Lunar Planet. Sci., XLIII, Abstract 1913.

Prockter, L. M., S. L. Murchie, C. M. Ernst, D. M. H. Baker, P. K. Byrne, J. W. Head, T. R. Watters, B. W. Denevi, C. R. Chapman, and S. C. Solomon (2012), The geology of medium-sized basins on Mercury: Implications for surface processes and evolution, Lunar Planet. Sci., XLIII, Abstract 1326.

Roberts, J. H., and O. S. Barnouin (2012), The effect of the Caloris impact on the mantle dynamics and volcanism of Mercury, J. Geophys. Res. 117, E02007, doi:10.1029/2011JE003876.

Robinson, M. S., et al. (2008), Reflectance and color variations on Mercury: Regolith processes and compositional heterogeneity, Science, 321, 66-69, doi:10.1126/science. 1160080

Schaber, G. G., J. M. Boyce, and N. J. Trask (1977), Moon-Mercury: Large impact structures, isostasy, and average crustal viscosity, Phys. Earth Planet. Inter., 15, 189-201, doi:10.1016/0031-9201(77)90031-0.

Schultz, P. H. (1988), Cratering on Mercury: A relook, in Mercury, edited by F. Vilas, C. R. Chapman, and M. S. Matthews, pp. 274-335, Univ. of Ariz. Press, Tucson.

Scott, D. H. (1977), Moon-Mercury: Relative preservation states of secondary craters, Phys. Earth Planet. Inter., 15, 173-178, doi:10.1016/00319201(77)90029-2.

Smith, D. E., et al. (2012), Gravity field and internal structure of Mercury from MESSENGER, Science, 336, 214-217, doi:10.1126/science. 1218809.

Solomon, S. C., R. P. Comer, and J. W. Head (1982), The evolution of impact basins: Viscous relaxation of topographic relief, J. Geophys. Res., 87, 3975-3992, doi:10.1029/JB087iB05p03975.

Solomon, S. C., et al. (2001), The MESSENGER mission to Mercury: Scientific objectives and implementation, Planet. Space Sci., 49, 1445-1465, doi:10.1016/S0032-0633(01)00085-X.

Spudis, P. D., and J. E. Guest (1988), Stratigraphy and geologic history of Mercury, in Mercury, edited by F. Vilas, C. R. Chapman, and M. S. Matthews, pp. 118-164, Univ. of Ariz. Press, Tucson. 
Spudis, P. D., and M. E. Strobell (1984), New identification of ancient multi-ring basins on Mercury and implications for geologic evolution, Lunar Planet. Sci., 15, 814-815.

Strom, R. G. (1977), Origin and relative age of lunar and Mercurian intercrater plains, Phys. Earth Planet. Inter., 15, 156-172, doi:10.1016/ 0031-9201(77)90028-0.

Strom, R. G., and G. Neukum (1988), The cratering record on Mercury and the origin of impacting objects, in Mercury, edited by F. Vilas, C. R. Chapman, and M. S. Matthews, pp. 336-373, Univ. of Ariz. Press, Tucson.

Strom, R. G., C. R. Chapman, W. J. Merline, S. C. Solomon, and J. W. Head (2008), Mercury cratering record viewed from MESSENGER's first flyby, Science, 321, 79-81, doi:10.1126/science.1159317.

Strom, R. G., M. Banks, C. R. Chapman, C. I. Fassett, J. A. Forde, J. W. Head, W. J. Merline, L. M. Prockter, and S. C. Solomon (2011), Mercury crater statistics from MESSENGER flybys: Implications for stratigraphy and resurfacing history, Planet. Space Sci., 59, 1960-1967, doi:10.1016/ j.pss.2011.03.018.

Trask, N. J., and J. E. Guest (1975), Preliminary geologic terrain map of Mercury, J. Geophys. Res., 80, 2461-2477, doi:10.1029/JB080i017p02461.

Watters, T. R., R. A. Schultz, M. S. Robinson, and A. C. Cook (2002), The mechanical and thermal structure of Mercury's early lithosphere, Geophys. Res. Lett., 29(11), 1542, doi:10.1029/2001GL014308.

Watters, T. R., F. Nimmo, and M. S. Robinson (2005), Extensional troughs in the Caloris basin of Mercury: Evidence of lateral crustal flow, Geology, 33, 669-672, doi:10.1130/G21678.1.
Watters, T. R., J. W. Head, S. C. Solomon, M. S. Robinson, C. R. Chapman B. W. Denevi, C. I. Fassett, S. L. Murchie, and R. G. Strom (2009a), Evolution of the Rembrandt impact basin on Mercury, Science, 324, 618-621.

Watters, T. R., S. C. Solomon, M. S. Robinson, J. W. Head, S. L. André S. A. Hauck II, and S. L. Murchie (2009b), The tectonics of Mercury: The view after MESSENGER's first flyby, Earth Planet. Sci. Lett., 285, 283-296, doi:10.1016/j.epsl.2009.01.025.

Watters, T. R., et al. (2012), Tectonic features on Mercury: An orbital view with MESSENGER, Lunar Planet. Sci., XLIII, Abstract 2121.

Wieczorek, M. A., A. C. M. Correia, M. Le Feuvre, J. Laskar, and N. Rambaux (2011), Mercury's spin-orbit resonance explained by initial retrograde and subsequent synchronous rotation, Nat. Geosci., 5, 18-21, doi:10.1038/ngeo 1350

Wilson, L., and J. W. Head (2008), Volcanism on Mercury: A new model for the history of magma ascent and eruption, Geophys. Res. Lett., 35, L23205, doi:10.1029/2008GL035620.

Wood, C. A., and J. W. Head (1976), Comparison of impact basins on Mercury, Mars, and the Moon, Proc. Lunar Plan. Sci. Conf., 7th, 3629-3651.

Zhong, S., and M. T. Zuber (2000), Long-wavelength topographic relaxation for self-gravitating planets and implications for the timedependent compensation of surface topography, J. Geophys. Res., 105, 4153-4164, doi:10.1029/1999JE001075.

Zuber, M. T., et al. (2012), Topography of the northern hemisphere of Mercury from MESSENGER laser altimetry, Science, 336, 217-220, doi: $10.1126 /$ science. 1218805 